\title{
Teaching Time Value Of Money Using An Excel Retirement Model
}

Fernando Arellano, Ph.D., University of Dallas, USA

Liz Mulig, DBA, CPA, University of Dallas, USA

Susan Rhame, Ph.D., CPA, University of Dallas, USA

\begin{abstract}
The time value of money (TVM) is required knowledge for all business students. It is traditionally taught in finance and accounting classes for use in various applications in the business curriculum. These concepts are also very useful in real life situations such as calculating the amount to save for retirement. This paper details a retirement model that can be built during class to teach TVM. While traditional teaching methods give small pieces of the TVM picture, then exercises to reinforce that partial knowledge, this model incorporates many TVM techniques into one Excel modeling exercise. The model incorporates both TVM functions that are included in Excel and other formulas that must be entered into Excel by the student modeler. Unlike some other articles that focus on how much should be saved annually assuming a constant salary, this exercise focuses on a percentage of income to be saved. The model also addresses an assumed growth factor in the salary and the issue of inflation. This modeling tool is presented to adults in graduate level classes, so it incorporates the fact that they might already have some savings coming into this retirement planning exercise. This method of teaching TVM has several objectives. Primarily, the exercise contributes to the learning of TVM concepts and techniques. It also shows how the equations modeled here can be used to solve retirement planning questions, while contributing to the personal financial literacy of students, and improving model building skills in Excel.
\end{abstract}

Keywords: Time Value of Money; Excel Modeling; Teaching TVM; Retirement

\section{INTRODUCTION}

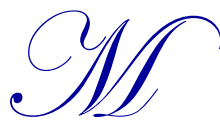

any students find the time value of money (TVM) concepts to be challenging. However, knowledge of these concepts is vital to numerous topics that are covered in upper-level finance and accounting courses such as notes, bonds, capital investment decisions, leases, and pensions. Furthermore, as the Financial Accounting Standards Board (FASB) and the International Accounting Standards Board (IASB) continue to work on convergence projects that require fair value reporting of various assets and liabilities, a working knowledge of TVM concepts will be essential. TVM concepts can be taught using present value tables, equations, financial calculators, Excel modeling, or various combinations of these approaches.

Bianco, Nelson, and Poole (2010) surveyed 700 students who were enrolled in one or both junior-level courses in which finance faculty teach TVM concepts. The purpose of the study was to determine whether or not the number of courses using TVM that a student had taken or the method of presentation affected their ability to solve TVM problems. Of the 700 surveyed, 284 usable respondents completed demographic information and five simple TVM problems as a quiz grade. While the results confirmed that GPA, quantitative background and academic major (accounting or finance) were significant variables, all methods of presentation (formula, calculator, computer, and tables) and the number of courses were not significant variables. This method of presentation finding was contrary to a previous study by Dempsey (2003).

Dempsey (2003) conducted an experiment using two groups of students. The method of presentation for one group was a mathematical (formula) approach, while the method of presentation for the second group was the 
use of tables. He found that the group exposed to the mathematical approach scored significantly higher and completed the test in significantly less time, as compared to the group exposed to the tables. By using mathematical solutions to TVM problems, Dempsey believes that students are better prepared to handle real-life TVM applications, as well as, more sophisticated TVM topics. McCarty (1995) concurred that the formula approach is pedagogically superior to the obsolete tables, and that students should understand what the financial calculator/computer is doing for them.

Mangiero, Manley, and Mollica (2010) agreed that it is important to illustrate the TVM mathematical technique calculations to a problem; however, by using dynamic Excel presentations, multiple examples can be reviewed in class with the sensitivity of the solution to changes in parameters highlighted. They presented a TVM retirement annuity analysis and a capital structure decision analysis. The authors believe that this allows for better use of classroom time, and provides a broader coverage of the issue being addressed. Balik $(2009,410)$ stated that "teaching students how to actually build financial models using a spreadsheet program like Excel is the best way to prepare them for the business world." In his paper, he discusses the Excel Best Practices. Sensitivity analysis as used by Mangiero, Manley, and Mollica (2010) is one of the Excel Best Practices.

Another retirement case was developed by Evans (2004) to illustrate TVM concepts through a practical application. Rather than using Excel, a financial calculator was used to solve the case. However, an instructor could easily solve the case using Excel as well. This case was focused on an undergraduate course. Stuebs (2011) also developed a retirement exercise that requires students to create Excel spreadsheets. It is more comprehensive than Evans (2004) because it includes more than one retirement source, but it makes the assumption that the salary remains constant. Once again, this exercise was aimed at an undergraduate audience.

The retirement exercise presented in this paper extends Stuebs (2011) and Mangiero, Manley, and Mollica (2010) by incorporating a model building approach that includes a real salary growth rate in addition to inflation. Also, the focus of this exercise goes a step further to determine the percentage of income that should be saved throughout the retirement saving period. This makes the retirement plan easy to apply. The retirement exercise presented in this paper is designed for a graduate level accounting or finance course. The paper presents a class exercise that incorporates TVM equations in building a retirement model, while using Excel. The retirement model uses Excel's built-in financial functions when they are applicable and TVM written-in equations as necessary. By using a retirement exercise, graduate students not only learn TVM concepts that are useful in many accounting and finance topics, but also personally useful in planning their own retirement. The model also incorporates the fact that as the person saving for retirement takes on more responsibility, his real income increases throughout the working period. Finally, the model considers any existing savings at the time of planning. Unlike, many textbook problems that only use one TVM concept, this comprehensive exercise incorporates many TVM concepts. The purpose of the exercise is to improve students' understanding of TVM concepts and techniques, to show the usefulness of TVM in solving real life problems, and to improve Excel model building skills.

\section{RETIREMENT MODEL}

When teaching the TVM, the equations are introduced in a step by step mode to facilitate understanding. Examples are given, many of them drawn from real life situations, to help in understanding the concept of TVM and its applications. However, the norm is that the exercises are usually isolated with no apparent relation between them. Building a retirement model allows for the integration of many TVM equations into one exercise. The problem addresses the question: How much should a person save for retirement?

Equations used in the retirement model are: future value (FV) given a present value (PV), future value of an annuity, present value of an annuity, present value of perpetuity, and future value of constant growing annuities. The equation for the effective interest rate formula is also used. All work is conducted in the classroom, with all students and the professor using their computers. The students complete the model on their computers as the professor covers the material and demonstrates the modeling in Excel.

Students are first required to write the equations for PV and FV when there are no annuities. They are then shown how to use Excel's financial functions to solve for FV, PV, i (rate), and annuities (PMT). After a number of 
exercises, they are introduced to the concept of perpetuities and constant growing annuities. They are shown the formulas, but are not required to enter them in Excel given the high probability that they will make mistakes and delay the exercise. These formulas are presented to them in an Excel template.

Once all the TVM equations have been presented to the students, and they have practiced them, they are asked to help the instructor in developing a retirement model. First, they are asked how much they think they should save for retirement as a percentage of their income. The answers vary between 5\% and 50\%, with the most common percentage being $10 \%$.

The exercise starts with the professor asking nine main questions and seeking the students' help in providing inputs for the model. This makes the exercise more dynamic and, since the exercise is related to a problem everyone faces in life, it also makes it more interesting for the students. Since the students are building their own model, they can enter the values they believe are more pertinent to their personal situations. In addition, because the model is built in Excel, sensitivity analysis is very easily conducted by simply changing the various attributes in the functions.

The overall question is the following: What percentage of one's income should they save for retirement? The answer to this question will come after answering a series of other questions. This paper defines the questions asked, and answered, to derive the percentage that should be saved.

\section{First Question}

This is actually a compound question: For how many years will an individual, which we will call Mr. Retiree, work and, once he retires, for how many years will he live off his retirement pension?

A diagram is drawn that shows the working years and the retirement years and shows two curves, one ascending during the working years, and one descending during the retirement years. The question elicits many responses. The model presented in the paper uses 40 years of work, starting at age 25, and 15 years of retirement, starting at age 65 and ending at age 80. Graph 1 shows the funds increasing in the years of contribution and decreasing in the years of withdrawal after retirement.

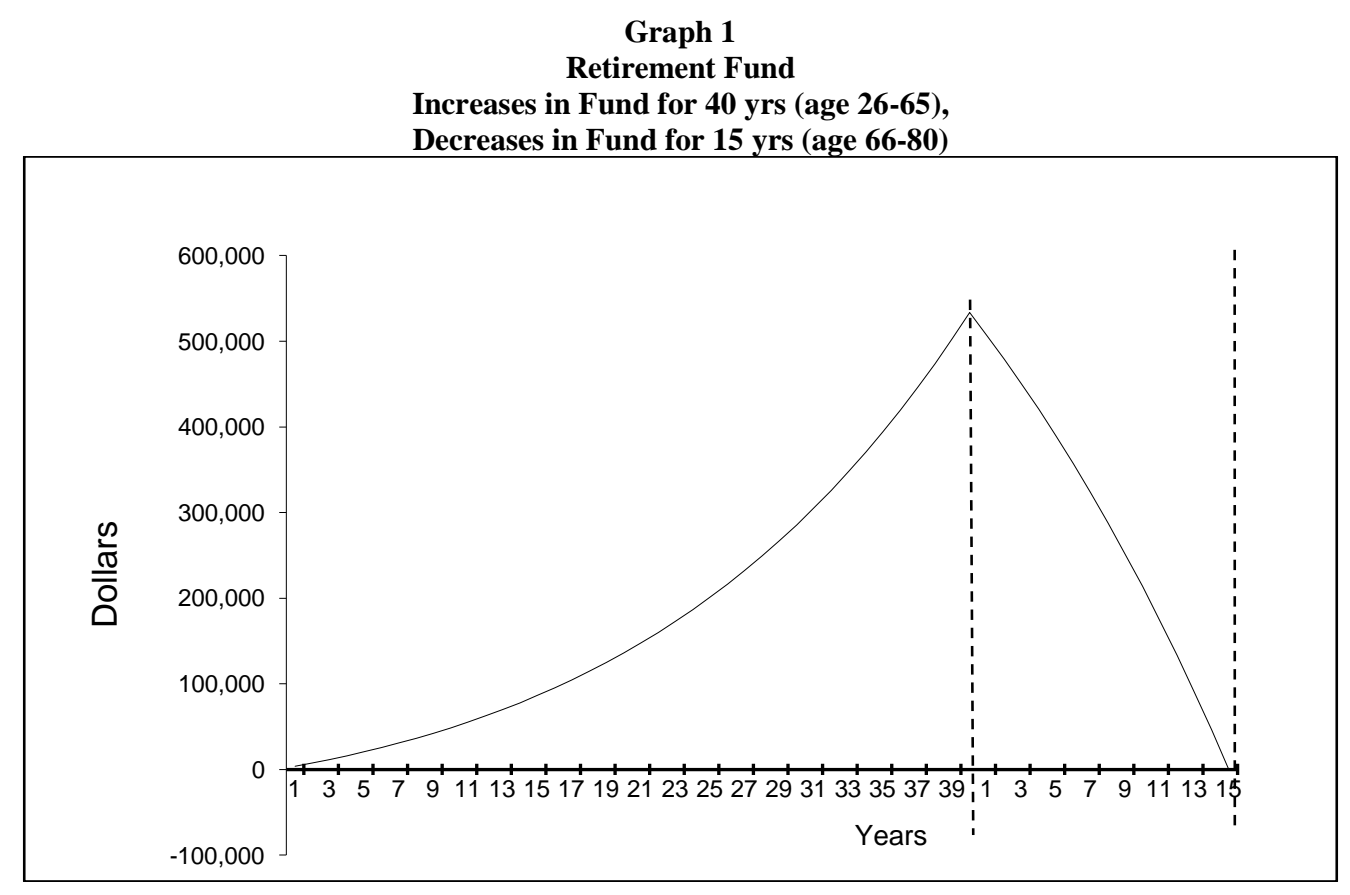




\section{Second Question}

This is a three part question. First, the students are asked: How much would you like to receive each year in retirement, ignoring any pension that you might receive from Social Security? The answers vary from $\$ 50,000$ to $\$ 150,000$ per year. Since a high annual pension would require a very high retirement fund amount, a lower figure is suggested and used in building the model. In order to keep the model simple, a yearly amount is used versus a monthly amount.

The equation to use in this case is the PV of an ordinary annuity in which the unknown variable is the fund amount that needs to be accumulated and the known variables are the rate of return, the number of periods, and the annual pension. The Excel financial function is PV with the following attributes (defined below): Rate, Term, PMT, FV, and Type. Next, the students are asked about the return of this fund. Again, the answers vary, with the range being between $5 \%$ and $20 \%$ per year. The model assumes no inflation, so a real rate is used. The model uses $4 \%$. Thus far, the model shows the following: $\$ 48,000$ is the PV (of yearly withdrawal in retirement years), $4 \%$ is the interest rate, and 15 is the number of payments.

Thirdly, students are asked what the PV of the yearly pension will be, which is $\$ 48,000$ annually in our example. After some reflection, they realize the ending balance after all retirement funds are withdrawn, however, is zero, and that in the PV function's dialog box, they should enter zero (or leave it blank). As for the type of payment, students are asked if the payments are ordinary or annuities due, that is, if the payment of the pension will take place at the end or at the beginning of the period. They answer the former, so they are told to enter 0 (or leave it blank). This assumes that Mr. Retiree retired the previous period and is living off his last salary.

Next (see Exhibit 1), the PV of an annuity equation is actually written out in long form so the students can see how this Excel function is equivalent. This equation will be shown again to demonstrate how to derive the PV of a perpetuity equation.

Exhibit 1

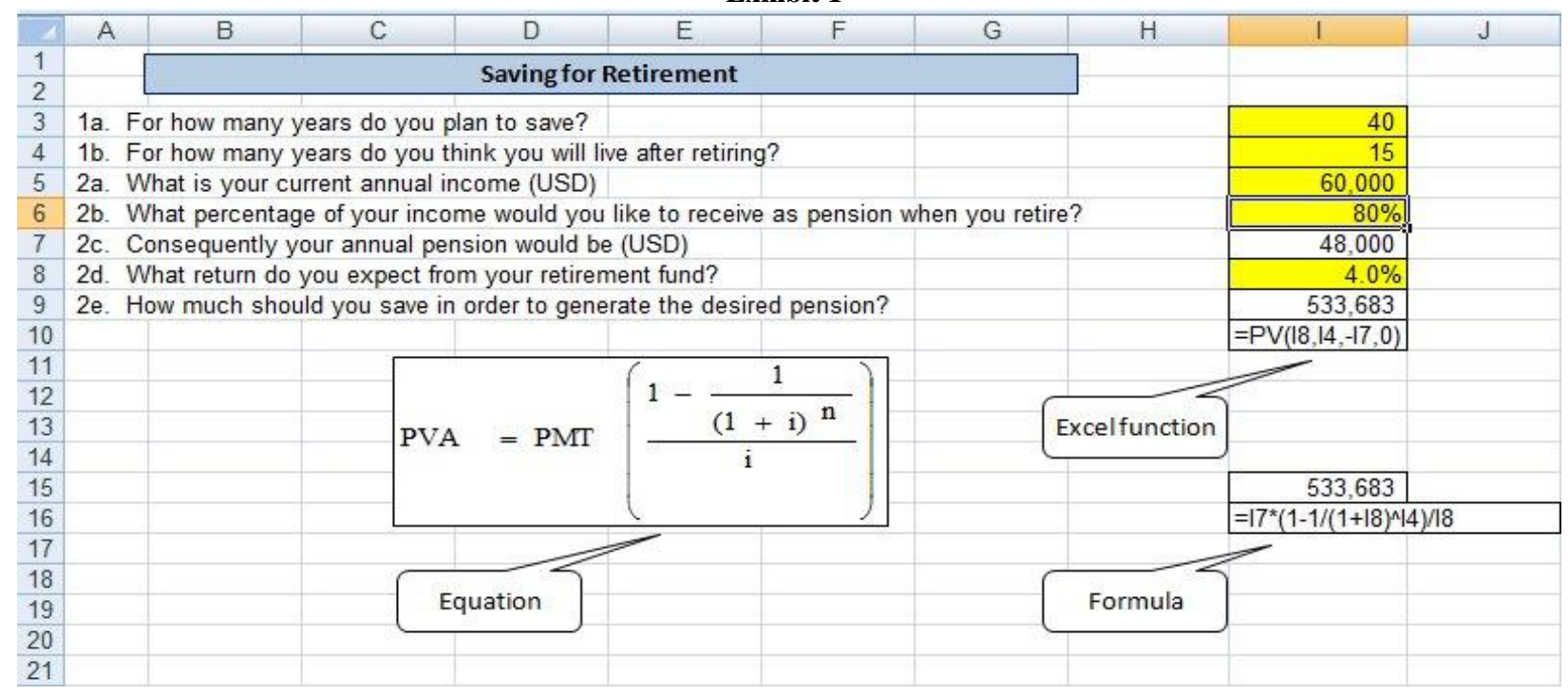

After applying the PV function, the answer is $\$ 533,682.60$. This is the amount needed at the beginning of Mr. Retiree's retirement period. When students realize the size of the fund and compare the pension it generates with the pensions they initially suggested, they generally lower their initial expectations about receiving high pensions when they retire.

\section{Third Question}

If Mr. Retiree decided to leave an inheritance to his family, what size would his fund need to be? In this case, the annual pension should be just what the fund yields. No principal would be included in the annual amount, 
just the return. This becomes a PV of a perpetuity exercise, in which the annual pension $(\$ 48,000)$ is the PMT and the return (4\%) is the interest rate. The resulting PV is $\$ 1,200,000$. This is an opportunity to write the equation (see Exhibit 2) for the PV of an annuity, and by making 'n' the number of term equal to infinity, derive the equation for the PV of a perpetuity. Excel doesn't have a function for PV of a perpetuity, so the equation must be written as a formula by the students.

Exhibit 2

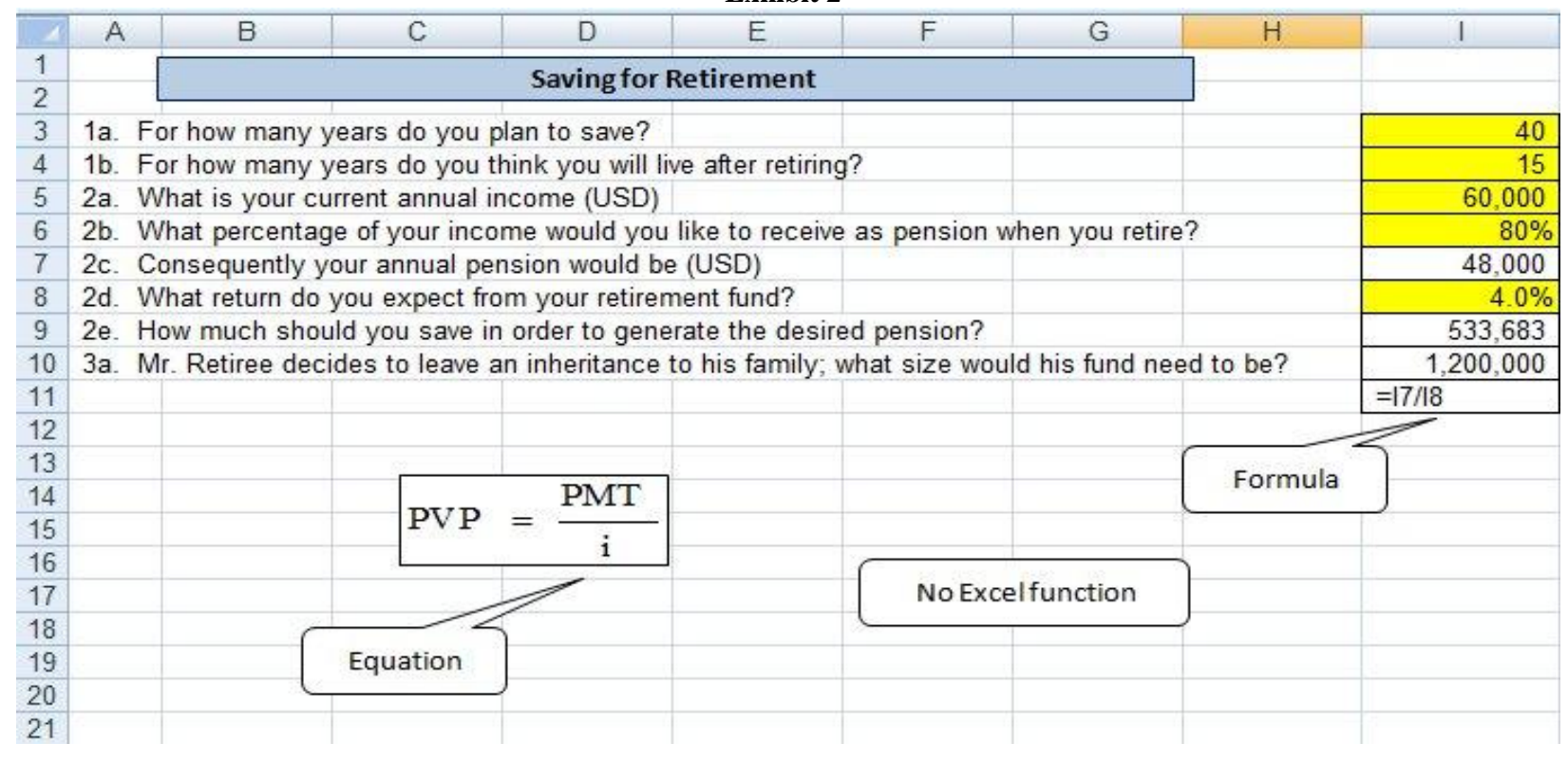

\section{Fourth Question}

How much would you have to save each year in order to accumulate the $\$ 533,683$ you need at the beginning of your retirement period? To estimate this figure, the Excel function for future value (FV) is used. First, though, the formula (see Exhibit 3) is covered, to show the students how the Excel function calculates the PV of an annuity.

\section{Exhibit 3}

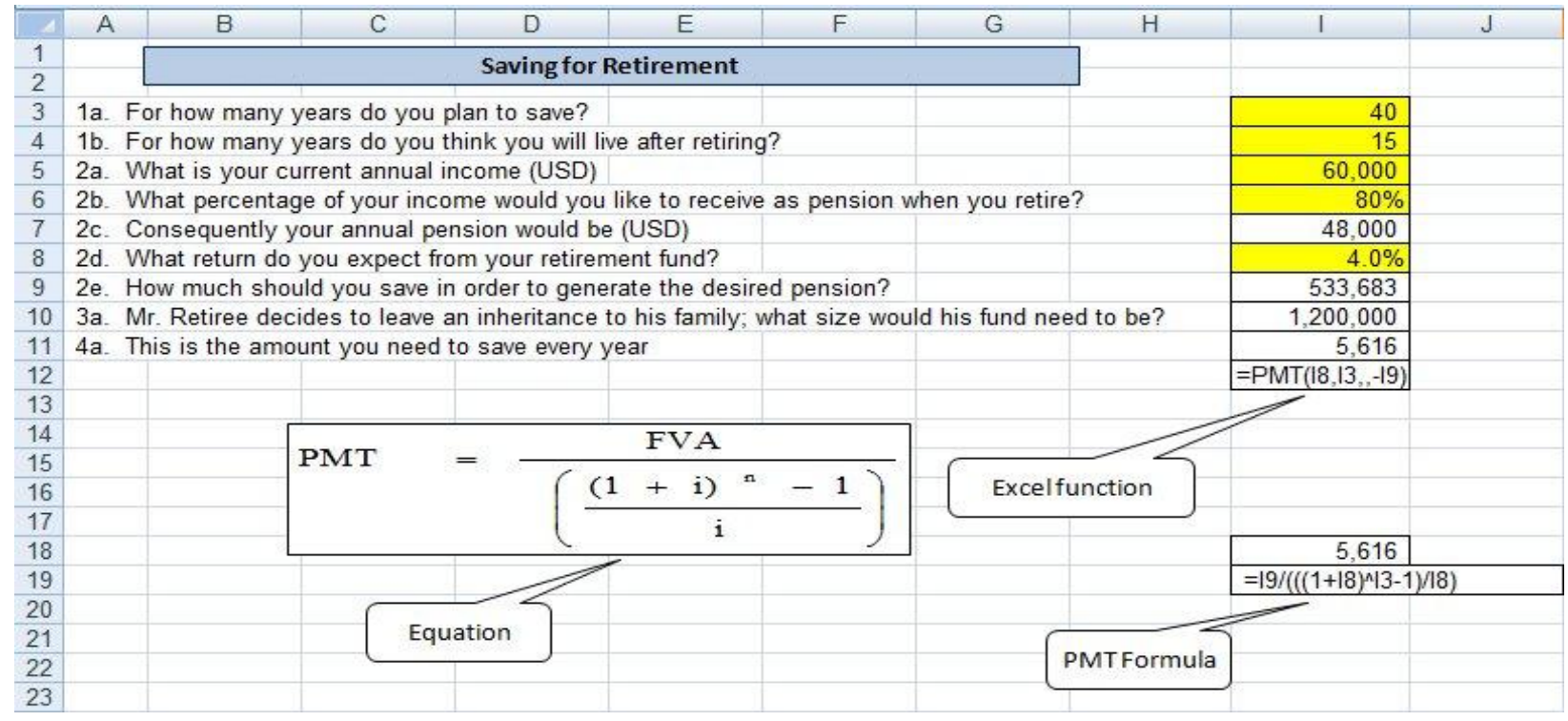


This equation is then related to the equation for calculating the $\mathrm{FV}$ of an annuity, ie the PV of the previous exercise becomes the FV. The term is 40 years and the return is the same, $4 \%$. The attributes of the Excel function for FV are the same as the attributes for the PV function, with the difference that PV is now one of the attributes.

An additional supporting question here is whether to apply the equation for ordinary annuities or annuities due? It is assumed that the first savings amount is deposited at the end of period 1, not earning any return until the following period, thus it is an ordinary annuity.

After making reference to the cell address of the PV $(\$ 533,682.60)$ and entering the other attributes, the result is $\$ 5,616.20$. This is the amount that needs to be saved every year for 40 years. Table 1 shows the ending balance increasing during the period of contribution and decreasing as withdrawals are made during retirement. The labels are PER for period, BB for beginning balance, PMT for payment, INT for interest, and EB for ending balance.

Table 1

Fixed Annual Contribution Years 1-40 \& Fixed Annual Withdrawals Years 1-15

\begin{tabular}{|c|c|c|c|c|c|}
\hline PER & $\mathrm{BB}$ & RETURN & SAVINGS & PENSION & EB \\
\hline 1 & - & - & 5,616 & - & 5,616 \\
\hline 2 & 5,616 & 225 & 5,616 & & 11,457 \\
\hline 3 & 11,457 & 458 & 5,616 & & 17,532 \\
\hline [] & [] & [] & [] & & [] \\
\hline 38 & 458,856 & 18,354 & 5,616 & & 482,827 \\
\hline 39 & 482,827 & 19,313 & 5,616 & & 507,756 \\
\hline 40 & 507,756 & 20,310 & 5,616 & & 533,683 \\
\hline 41 & 533,683 & 21,347 & & $(48,000)$ & 507,030 \\
\hline 42 & 507,030 & 20,281 & & $(48,000)$ & 479,311 \\
\hline 43 & 479,311 & 19,172 & & $(48,000)$ & 450,484 \\
\hline [] & [] & [] & & [] & [] \\
\hline 53 & 133,204 & 5,328 & & $(48,000)$ & 90,533 \\
\hline 54 & 90,533 & 3,621 & & $(48,000)$ & 46,154 \\
\hline 55 & 46,154 & 1,846 & & $(48,000)$ & $(0)$ \\
\hline
\end{tabular}

The fund increases yearly as contributions are made, and decreases as withdrawals occur, as shown in the following Graph 2.

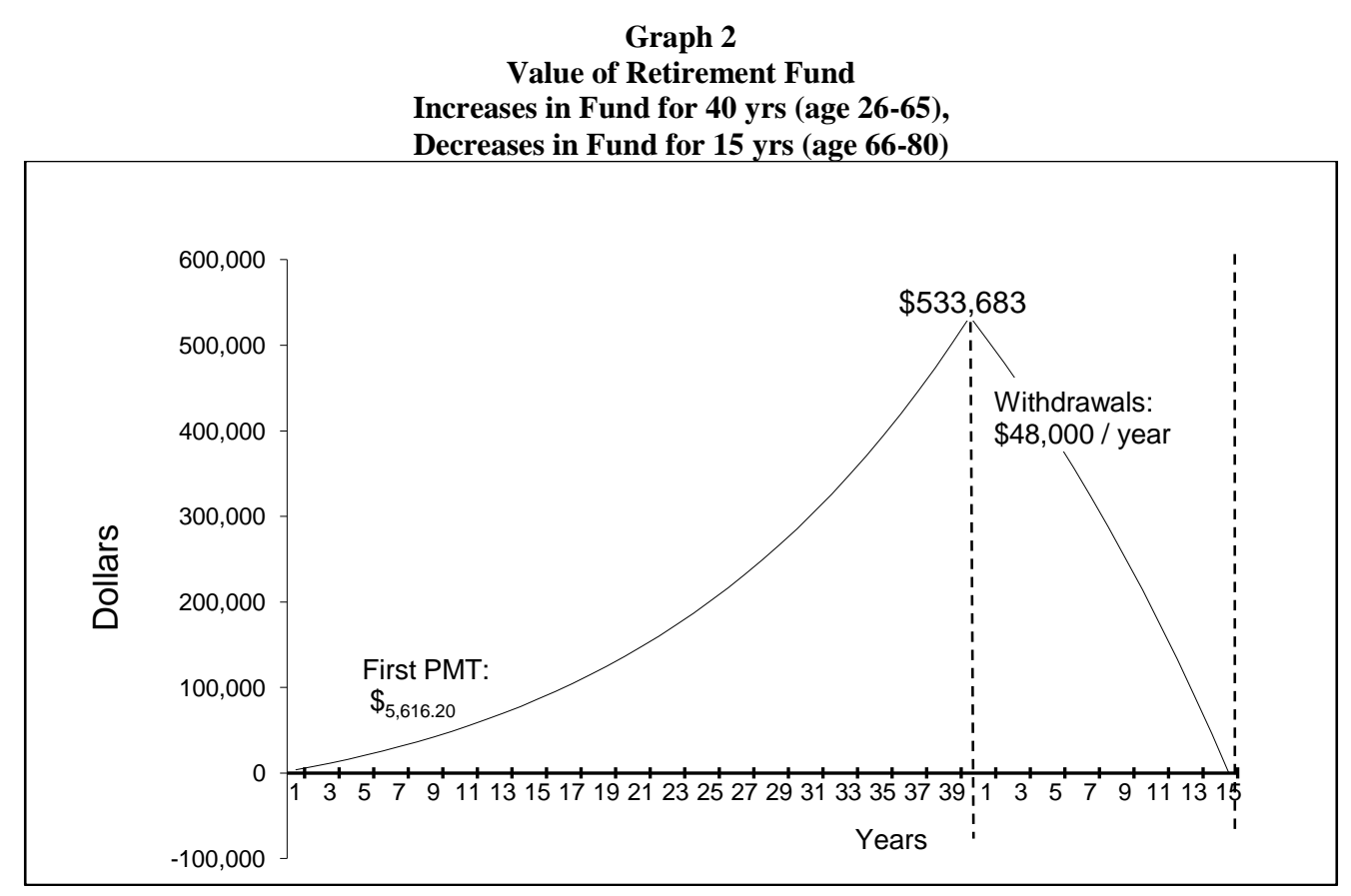




\section{Fifth Question}

What percentage of income is the $\$ 5,616$ amount that is to be saved each year? The resulting percentage is $9.36 \%$ in year 1. See Exhibit 4.

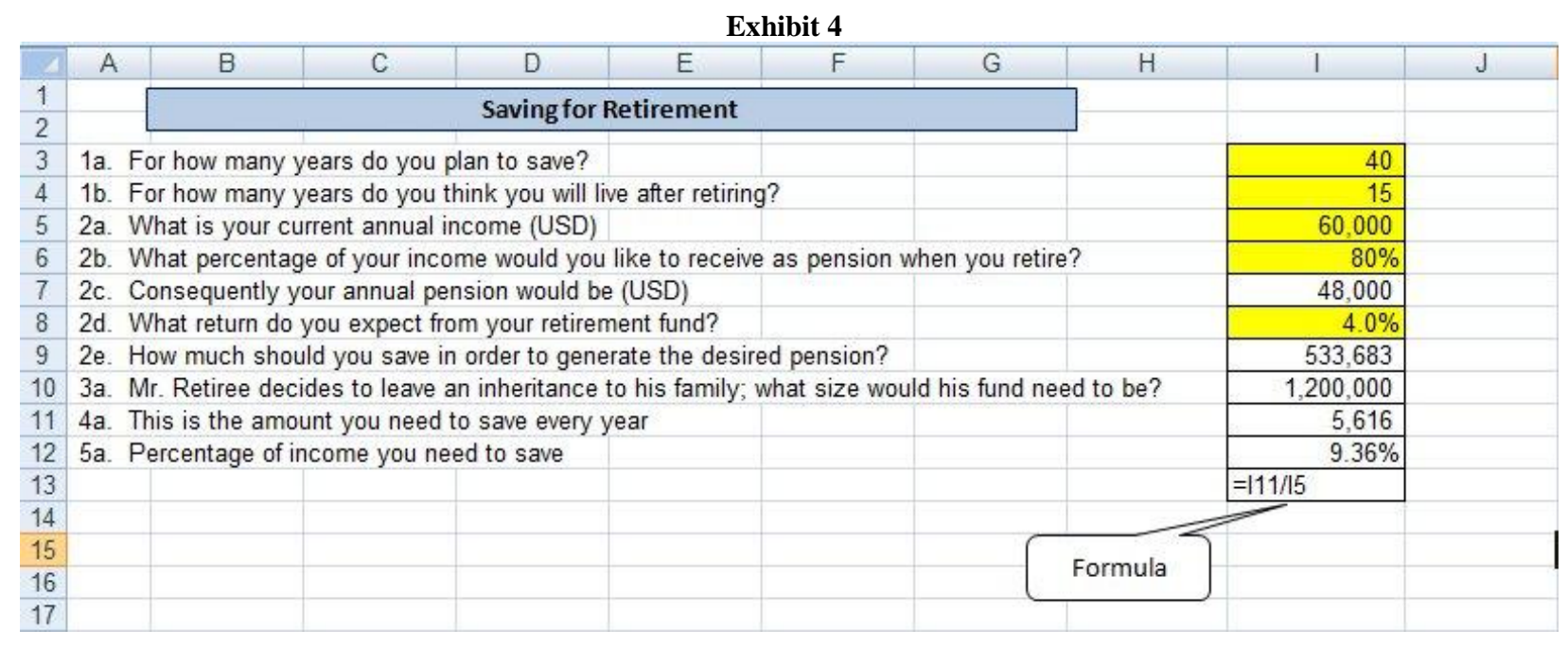

A follow up question is: What percentage of the final income, just before Mr. Retiree retires, is this annual $\$ 5,616$ amount? The ending income suggested is usually $\$ 100,000$ to $\$ 150,000$. For purposes of the demonstration, $\$ 120,000$ is used, so the $\$ 5,616$ is only $4.68 \%$, i.e. as Mr. Retiree's income increases, the $\$ 5,616$ is a lower percentage of his annual income.

\section{Sixth Question}

Since the percentage saved at the beginning and at the end of Mr. Retiree's career is so different, the following question is posed: Wouldn't it be better if Mr. Retiree could save an amount that is a constant percentage of his income?

This requires the application of an equation to compute rate of growth. In this case, the Rate function is used, with $\$ 60,000$ and $\$ 120,000$ as the present and future values, respectively. In Excel, as with financial calculators, one of these values has to be entered with a negative sign. Since Excel doesn't have a growth rate function, this method of calculation uses the Rate function (a TVM function in Excel) to compute a growth rate. This function also has payment and type as attributes. The students are told to leave these two attributes blank, since there is no payment used, just PV and FV, and the type also refers to the payment (whether it is at the beginning or end of the period), so the type isn't needed either

In order to familiarize the students with the Excel Rate function, the FV equation is covered here (see Exhibit 5), solving for the interest rate. 
Exhibit 5

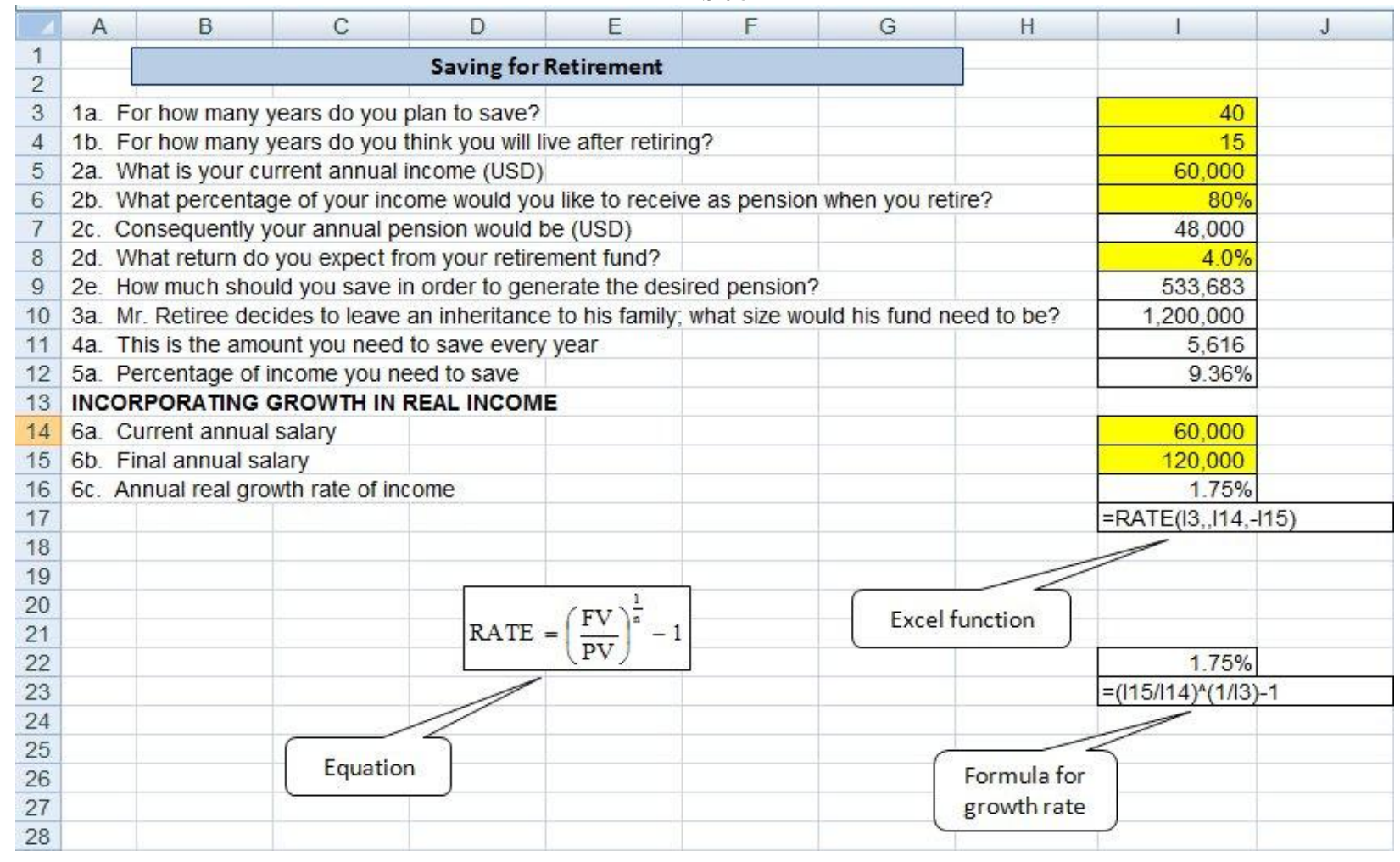

Using $\$ 60,000$ as the $\mathrm{PV}, \$ 120,000$ as $\mathrm{FV}$, and 40 as the number of periods, the resulting growth rate of income is $1.75 \%$. This is the annual growth of salaries for Mr. Retiree. This is assumed to be a real growth rate, since it is not measuring how a particular income changes with time, due to inflation, but measuring how income changes because of more experience and responsibilities.

A follow up question is posed here: How can the amount to be saved be calculated, such that each time the annual income increases by $1.75 \%$ the amount saved also increases by $1.75 \%$. In other words, what is the calculation to determine a savings amount that is a constant percentage of the annual income? Excel does not have a function that calculates payments that grow at a constant rate. Therefore, the students are next introduced to the equation to calculate graduated payments or constant growth payments (see below.)

$$
P M T_{1}=\frac{F V}{\left(\frac{(1+i)^{n}-(1+g)^{n}}{i-g}\right)}
$$

Where:

$\mathrm{PMT}_{1}=$ payment in period 1.

$\mathrm{FV}=$ amount needed to be accumulated: $\$ 533,682.60$.

$\mathrm{N} \quad=$ term: 40 years.

$\mathrm{g} \quad=$ growth rate, $1.75 \%$.

Applying this equation, the resulting amount is $\$ 4,291$. See Exhibit 6 . This is the amount that needs to be saved by the end of the first year. Since it is easy to make mistakes in entering a formula in Excel, partial results such as the result of $(1+\mathrm{i})^{\mathrm{n}}$ and $(1-\mathrm{g})^{\mathrm{n}}$, are given so that students can enter the formula in a step by step mode. This equation is then compared to the equation for the $\mathrm{FV}$ of an annuity by making the growth rate (g) equal to 0 . 
Exhibit 6

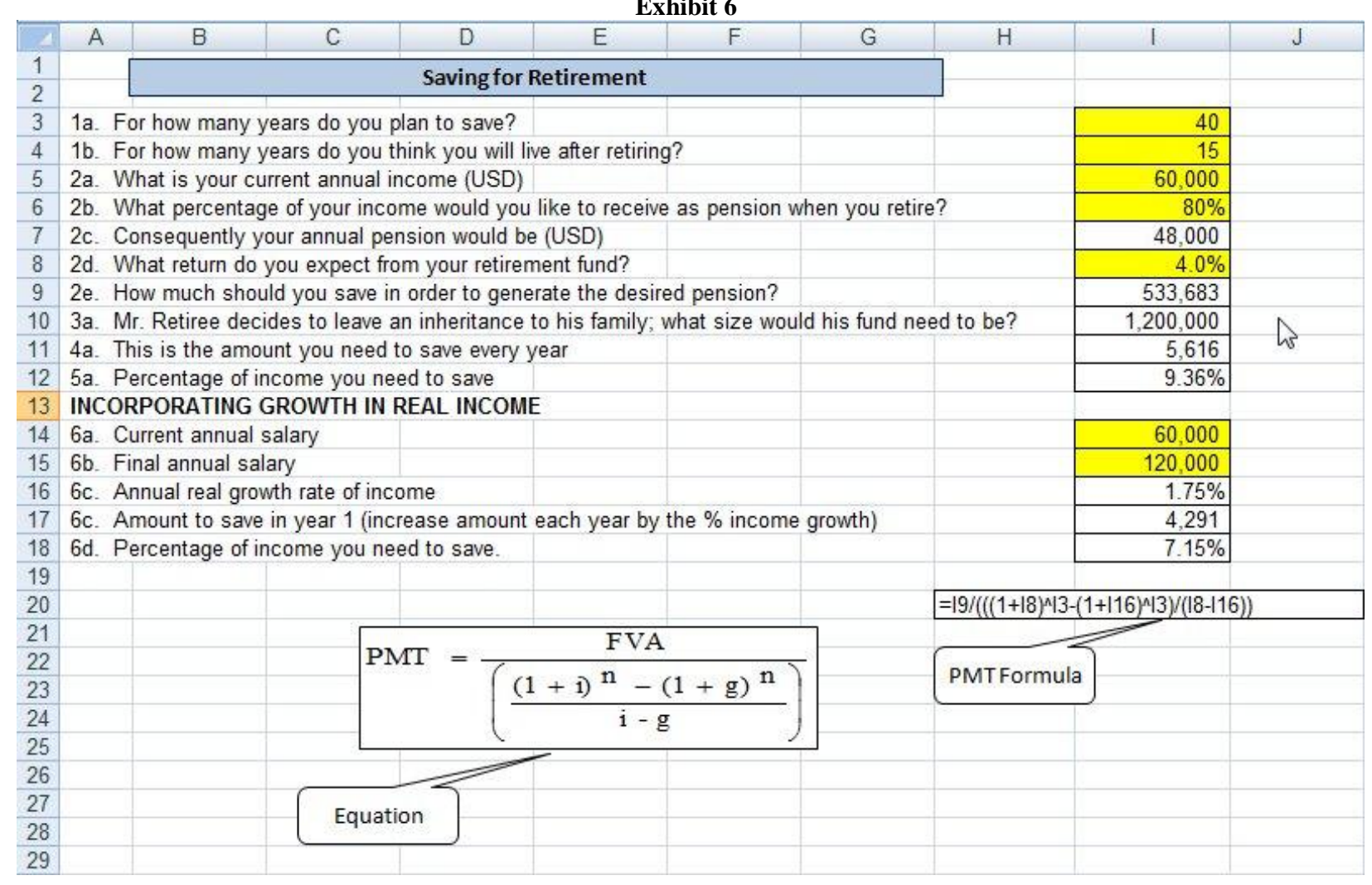

Compared to the initial salary, $\$ 4,291$ is $7.15 \%$ of income. This percentage will stay constant as long as the salary also increases by $1.75 \%$. Table 2 (see below) shows how, year by year, the fund grows to the required amount and how the fund is reduced by the annual withdrawals.

Table 2

Fixed Percentage Contribution Years 1-40 \& Fixed Annual Withdrawals Years 1-15 (With increasing real income)

\begin{tabular}{r|c|r|r|r|r|} 
PER & BB & INT & SAVINGS & PENSION & EB \\
\hline 1 & - & - & 4,291 & - & 4,291 \\
\hline 2 & 4,291 & 172 & 4,366 & & 8,828 \\
\hline 3 & 8,828 & 353 & 4,442 & & 13,624 \\
\hline[] & {[]} & {[]} & {[]} & & {[]} \\
\hline 38 & 451,446 & 18,058 & 8,147 & & 477,651 \\
\hline 39 & 477,651 & 19,106 & 8,289 & & 505,047 \\
\hline 40 & 505,047 & 20,202 & 8,434 & & 533,683 \\
\hline 41 & 533,683 & 21,347 & & $(48,000)$ & 507,030 \\
\hline 42 & 507,030 & 20,281 & & $(48,000)$ & 479,311 \\
\hline 43 & 479,311 & 19,172 & & $(48,000)$ & 450,484 \\
\hline[] & {[]} & {[]} & & {[]} & {[]} \\
\hline 53 & 133,204 & 5,328 & & $(48,000)$ & 90,533 \\
\hline 54 & 90,533 & 3,621 & & $(48,000)$ & 46,154 \\
\hline 55 & 46,154 & 1,846 & & $(48,000)$ & 0 \\
\hline
\end{tabular}




\section{Seventh Question}

How does this model deal with inflation? The fund returns during the working retirement periods are real returns. Building in inflation transforms the rates to nominal. The assumption of the model is that the nominal rates applied to the fund are the same as the real rates used after factoring in inflation. This is a risky assumption, but it is a common problem in any retirement model. For that reason, it is better to use conservative real rates of return, even zero returns. In the proposed model, inflation is assumed to result in a nominal rate being applied to the fund such that the amounts withdrawn keep their acquisition power. Exhibit 7 incorporates an annual inflation rate of 3\%.

Exhibit 7

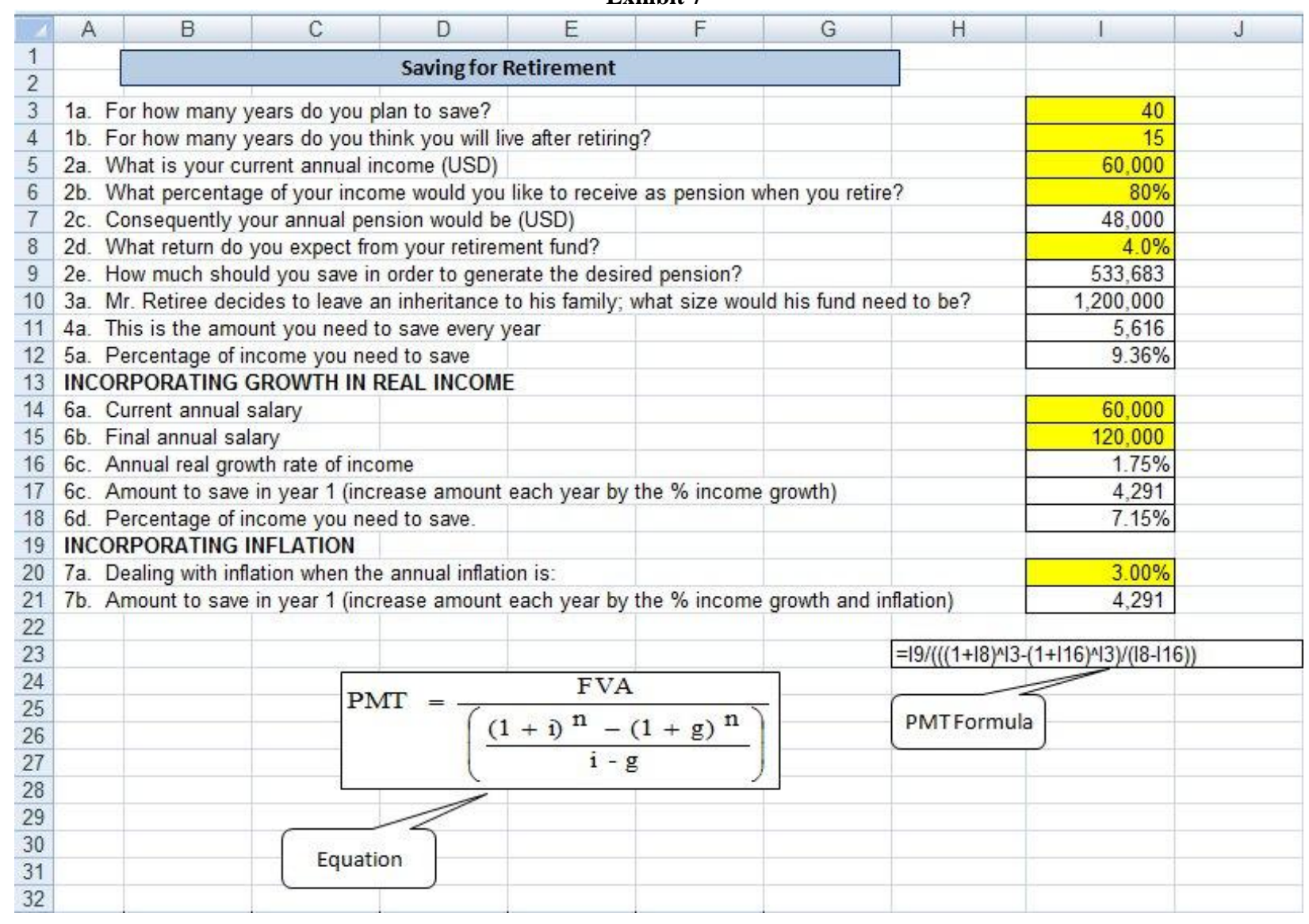

The initial amount to be saved for Year 1 is the same as before. Future saving amounts will be increased by the real increase in income and by inflation.

In building the savings table, in addition to the impact of the inflation rate on the interest rate, the payments are increased by the combined effect of the growth rate in income and the inflation rate. In building the pension table, the interest rate is also impacted by inflation, together with the annual amounts withdrawn. See Table 3 below which incorporates the growth rate in income and the rate of inflation. 
Table 3

Fixed Percentage Contributions Years 1-40 \& Fixed Annual Withdrawals Years 1-15

(With Increasing Real Income and Inflation)

\begin{tabular}{r|c|c|r|r|r|} 
PER & BB & \multicolumn{1}{c|}{ INT } & SAVINGS & PENSION & EB \\
\hline 1 & - & - & 4,291 & - & 4,291 \\
\hline 2 & 4,291 & 306 & 4,497 & & 9,093 \\
\hline 3 & 9,093 & 647 & 4,713 & & 14,453 \\
\hline[] & {[]} & {[]} & {[]} & & {[]} \\
\hline 38 & $1,308,417$ & 93,159 & 24,320 & & $1,425,897$ \\
\hline 39 & $1,425,897$ & 101,524 & 25,488 & & $1,552,909$ \\
\hline 40 & $1,552,909$ & 110,567 & 26,711 & & $1,690,187$ \\
\hline 41 & $1,690,187$ & 120,341 & & $(156,578)$ & $1,653,951$ \\
\hline 42 & $1,653,951$ & 117,761 & & $(161,275)$ & $1,610,437$ \\
\hline 43 & $1,610,437$ & 114,663 & & $(166,113)$ & $1,558,987$ \\
\hline[] & {[]} & {[]} & & {[]} & {[]} \\
\hline 53 & 601,474 & 42,825 & & $(223,243)$ & 421,057 \\
\hline 54 & 421,057 & 29,979 & & $(229,940)$ & 221,096 \\
\hline 55 & 221,096 & 15,742 & & $(236,838)$ & 0 \\
\hline
\end{tabular}

\section{Eighth Question}

How will the model change if Mr. Retiree had previously accumulated savings for retirement? Exhibit 8 incorporates an accumulated equity of $\$ 4,000$ at the start year 1 of the retirement plan. This reduces the percentage of income that Mr. Retiree would need to save each year to reach the same $\$ 533,683$ at the end of his working years.

\section{Exhibit 8}

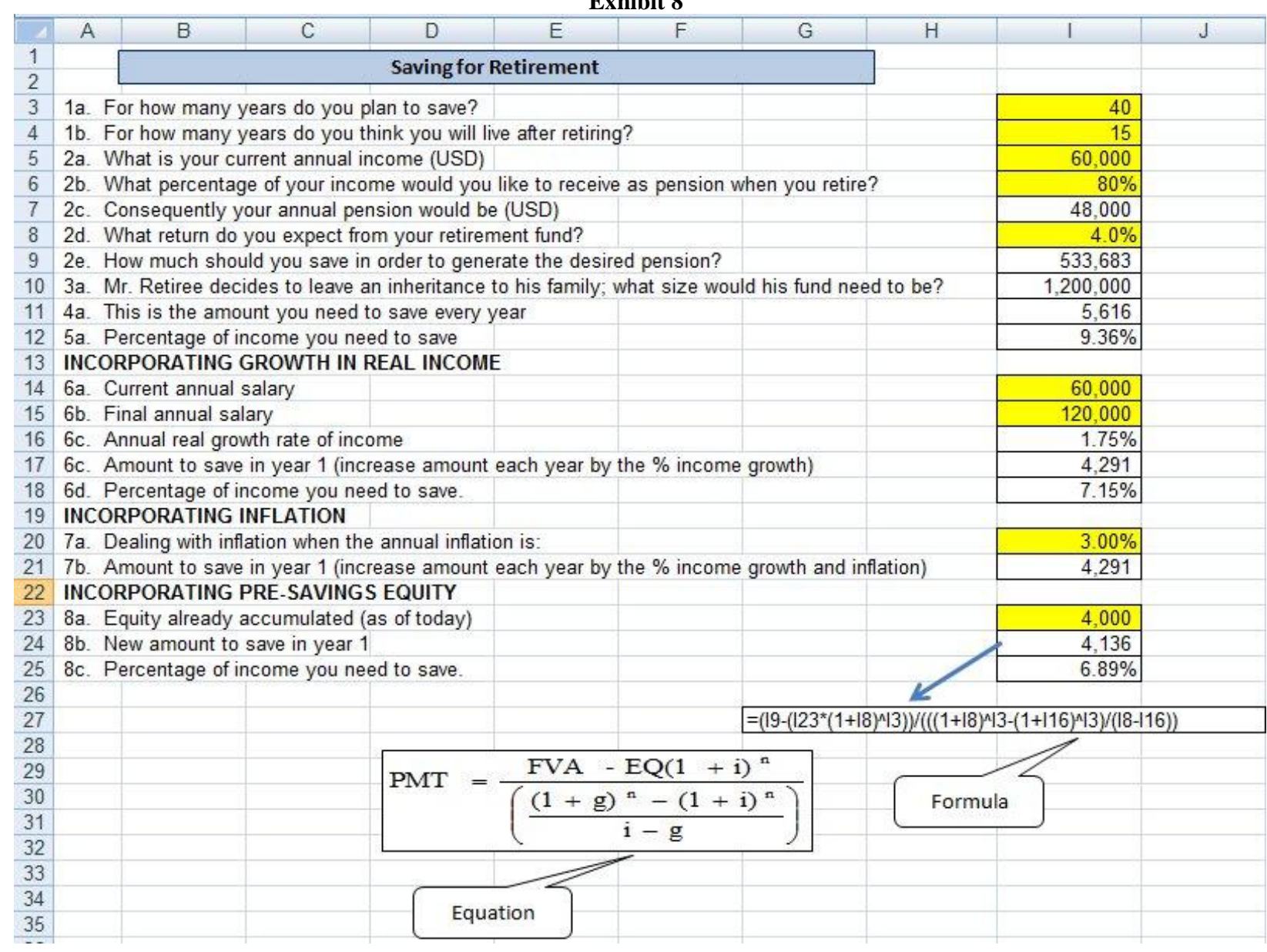

(C) 2012 The Clute Institute http://www.cluteinstitute.com/ 


\section{Ninth Question}

A variation of the model would be to make monthly contributions and withdrawals instead of annual contributions and withdrawals. In order to calculate the monthly contributions, the interest rate has to be changed to a monthly rate to use the model. Exhibit 9 calculates the monthly equivalent return rate, which requires working the equation for the effective interest rate.

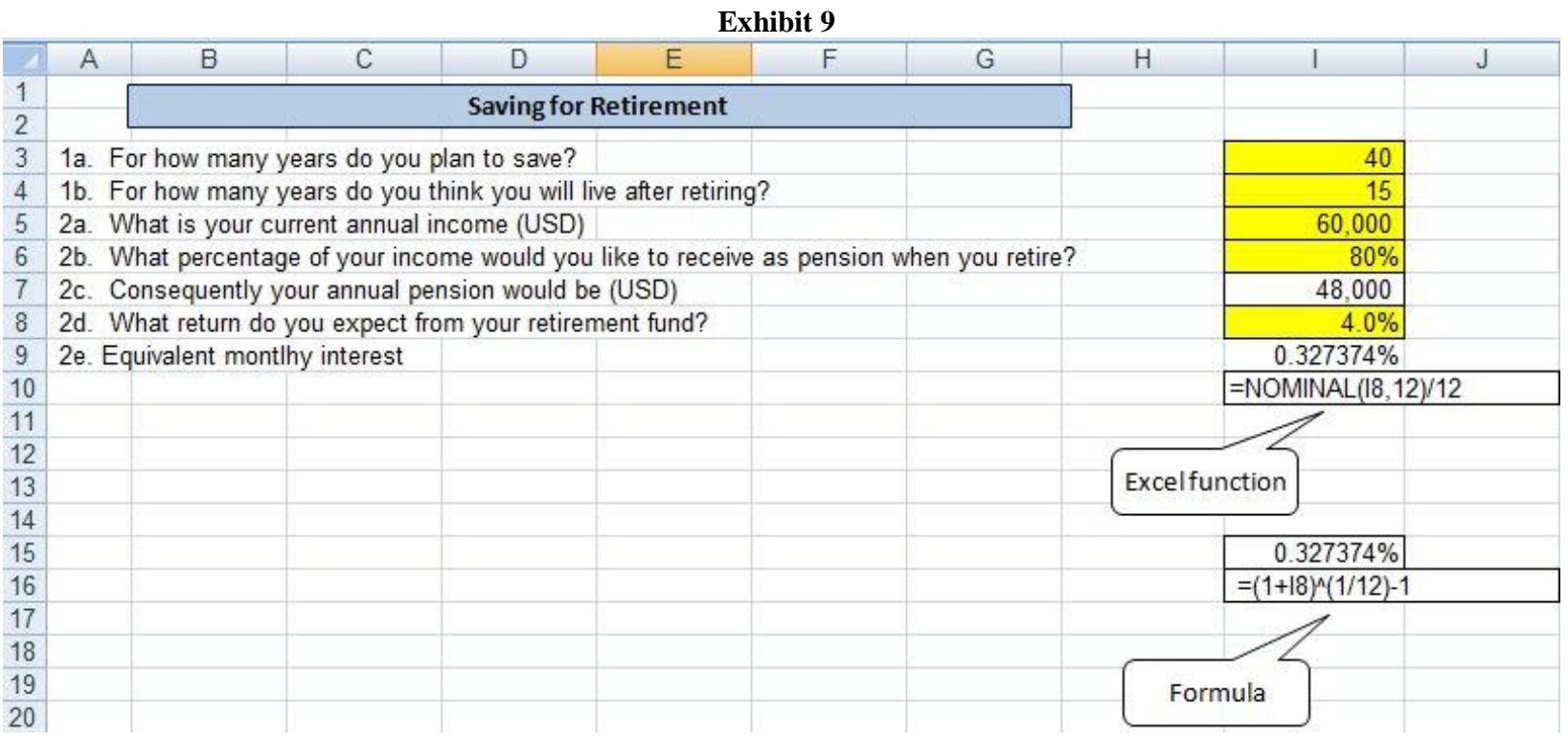

\section{CONCLUSION}

Students often have difficulty with applying TVM concepts and techniques, and these are required knowledge for all business students. TVM is traditionally taught in finance and accounting classes for use in various applications in the business curriculum. These concepts are also very useful in real life situations such as calculating the amount to save for retirement.

This paper details a retirement model that can be built during class to teach the time value of money. While traditional teaching methods give small pieces of the TVM picture, then present exercises to reinforce that partial knowledge, this model incorporates many TVM techniques into one Excel modeling exercise. The modeling exercise incorporates both TVM functions that are included in Excel and other formulas that must be entered into Excel by the student modeler. The presentation of the modeling techniques are presented in a step by step manner, following Questions 1-9 as detailed in the paper.

This modeling tool is presented to adults in graduate level classes, so it incorporates the fact that they might already have some savings coming into this retirement planning exercise. The model uses almost all TVM equations presented in financial management and accounting textbooks. Techniques incorporated include present value, future value, effective interest rates, graduated payments, growth rates and the present value of perpetuity.

This method of teaching TVM has several objectives. Primarily, the exercise contributes to the learning of TVM concepts and techniques. It also shows how the equations modeled can be used to solve retirement planning questions, while contributing to the personal financial literacy of students, and improving model building skills in Excel. Unlike some other articles that focus on how much should be saved annually assuming a constant salary, this exercise focuses on a percentage of income to be saved. The model also addresses an assumed growth factor in the salary and the issue of inflation. The exercise is complemented with graphs and tables showing how a retirement fund is built during the savings period and how the fund is reduced to zero during the withdrawal period. 


\section{NOTE}

Readers wishing to obtain a copy of the Excel spreadsheet model may contact Fernando Arellano at farellano@udallas.edu.

\section{AUTHOR INFORMATION}

Fernando Arellano is an Assistant Professor in the College of Business at the University of Dallas where he teaches finance courses. He holds Master of Science in Finance and Ph.D. in Economics degrees from Colorado State University. His areas of interest are in corporate finance and business and financial modeling. He has developed various computerized business simulations. He is a member of the Financial Management Association (FMA) and of the Association for Business Simulation and Experiential Learning (ABSEL). E-mail: farellano@udallas.edu

Liz Mulig received her doctorate in Accounting from Louisiana Tech University, and she is an Assistant Professor of Accounting at the University of Dallas. Her undergraduate degree in accounting is from Louisiana State University in Shreveport, and she earned an MBA and MPA from Louisiana Tech University. After completing her degree at LSU Shreveport, Dr. Mulig worked one year in public accounting and ten years in industry. She has taught accounting at several universities, primarily in the financial and managerial accounting areas. Her research interests include ethics, pedagogy and identity theft. E-mail: $\underline{\operatorname{lmulig} @ \text { udallas.edu }}$

Susan Rhame received her Ph.D. in Accounting from the University of Texas at Arlington, and she is an Assistant Professor of Accounting at the University of Dallas. Her undergraduate and master degrees are from Mississippi State University and Louisiana State University, respectively. After completing her degree at LSU, Dr. Rhame worked in the tax department of the Dallas office of Arthur Young \& Co. (now known as Ernst \& Young). She has taught accounting at LSU, UTA, Collin College, and Austin College. Her research interests include tax equity, financial statement presentation, online pedagogy, and retirement planning. E-mail: srhame@udallas.edu (Corresponding author)

\section{REFERENCES}

1. $\quad$ Balik, R. J. (2009). Excel best practices. Managerial Finance, 35(5), 410-410-426.

2. Bianco, C. A., Nelson, D. T., \& Poole, B. S. (2010). Teaching time value of money. The Business Review, Cambridge, 16(1), 25-25-31.

3. Dempsey, S. J. (2003). On the benefits of a mathematical solutions approach to time value of money instruction: Arguments and evidence. Journal of Accounting Education, 21(3), 239-239-260.

4. Evans, M. D. (2004). The retirement decision. Journal of the International Academy for Case Studies, 10(2), 21-29.

5. Mangiero, G. A., PhD., Manley, J., \& Mollica, J. T. (2010). Improving pedagogy through the use of dynamic excel presentations in financial management courses. American Journal of Business Education, 3(1), 91-91-106.

6. McCarty, D.E. (1995). Alternative Ways Students Can Do Compounding/Discounting: The Third Leg. Journal of Financial Education, Fall, 58-63.

7. Stuebs, M. (2011). Revealing money's time value. Journal of Accounting Education, 29(1), 14-36. 
NOTES 